\title{
The Role of the Immune Cells in Fracture Healing
}

\author{
Gurpreet S. Baht ${ }^{1,2,3} \cdot$ Linda Vi $^{4} \cdot$ Benjamin A. Alman ${ }^{1,3}$ \\ Published online: 5 March 2018 \\ (C) The Author(s) 2018. This article is an open access publication
}

\begin{abstract}
Purpose of review Bone fracture healing is a complex physiological process relying on numerous cell types and signals. Inflammatory factors secreted by immune cells help to control recruitment, proliferation, differentiation, and activation of hematopoietic and mesenchymal cells. Within this review we will discuss the functional role of immune cells as it pertains to bone fracture healing. In doing so, we will outline the cytokines secreted and their effects within the healing fracture callus.

Recent findings Macrophages have been found to play an important role in fracture healing. These immune cells signal to other cells of the fracture callus, modulating bone healing.

Summary Cytokines and cellular signals within fracture healing continue to be studied. The findings from this work have helped to reinforce the importance of osteoimmunity in bone fracture healing. Owing to these efforts, immunomodulation is emerging as a potential therapeutic target to improve bone fracture healing.
\end{abstract}

\section{Introduction}

In the context of tissue repair, bone is unique as it is able to heal itself without forming a scar. The lifetime prevalence of bone fracture is $50 \%$ in the US and while most bone injuries are able to heal normally, $5 \%-10 \%$ result in non-union every year. This rate increases with certain comorbidities and with advanced age [1,2]. Approximately 100,000 fractures require surgical intervention every year in the US, amounting to over a billion dollars in health care costs [3]. Treatments thus far involve the use of frames to stabilize bone and of osteo-

This article is part of the Topical Collection on Orthopedic Management of Fractures

\section{Gurpreet S. Baht}

gurpreet.baht@duke.edu

Benjamin A. Alman

ben.alman@duke.edu

1 Department of Orthopaedic Surgery, Duke Molecular Physiology Institute, Duke University, DUMC 104775, 300 North Duke Street, Durham, NC 27701, USA

2 Duke Molecular Physiology Institute, Durham, NC, USA

3 Department of Orthopaedic Surgery, Duke University, 200 Trent Drive, Orange Zone 5th floor, Durham, NC 27710, USA

4 University of Toronto, Toronto, Canada inductive agents (such as BMP) to increase the amount of bone deposition at the site of injury.

Recent work highlighting the importance of immune cells in fracture healing may develop into a potentially new area of treatment for bone injury [5-7]. Immune cells, which are derived from hematopoietic stem cells, are required for normal bone development and proper fracture healing. Dysfunction of these cells, as seen with age or with metabolic dysregulation, hinders bone repair. Rejuvenation of the hematopoietic population through parabiosis or bone marrow transplantation is able to ameliorate these shortcomings $[4,5]$. Current efforts are directed at delineating the exact role these cells play in fracture healing. A better understanding of osteoimmunity could result in the emergence of therapeutic targets for bone healing.

When a bone is injured, an inflammatory response is cast: immune cells are recruited to the site of injury; multiple factors are secreted, inflammatory and other. This intense inflammatory event is required to ensure normal fracture healing through angiogenesis of vessels, repair of the injured tissue, and eventually remodeling [6-8]. While the inflammatory response itself is short-lived, the effects of the immune cells extend beyond the early stages of fracture healing. Mesenchymal progenitor cell recruitment and activation rely on this inflammatory response. Thus, immune cells are integral to bone fracture healing. This review will outline the role of the immune system during fracture healing, then specifically the role of each individual cell type. 
Figure 1. Role of immune cells during fracture repair. Bone fracture healing can be viewed as a four-stage process. Immune cells play important roles throughout this process; however, a majority of their activity occurs during early stages of fracture healing.

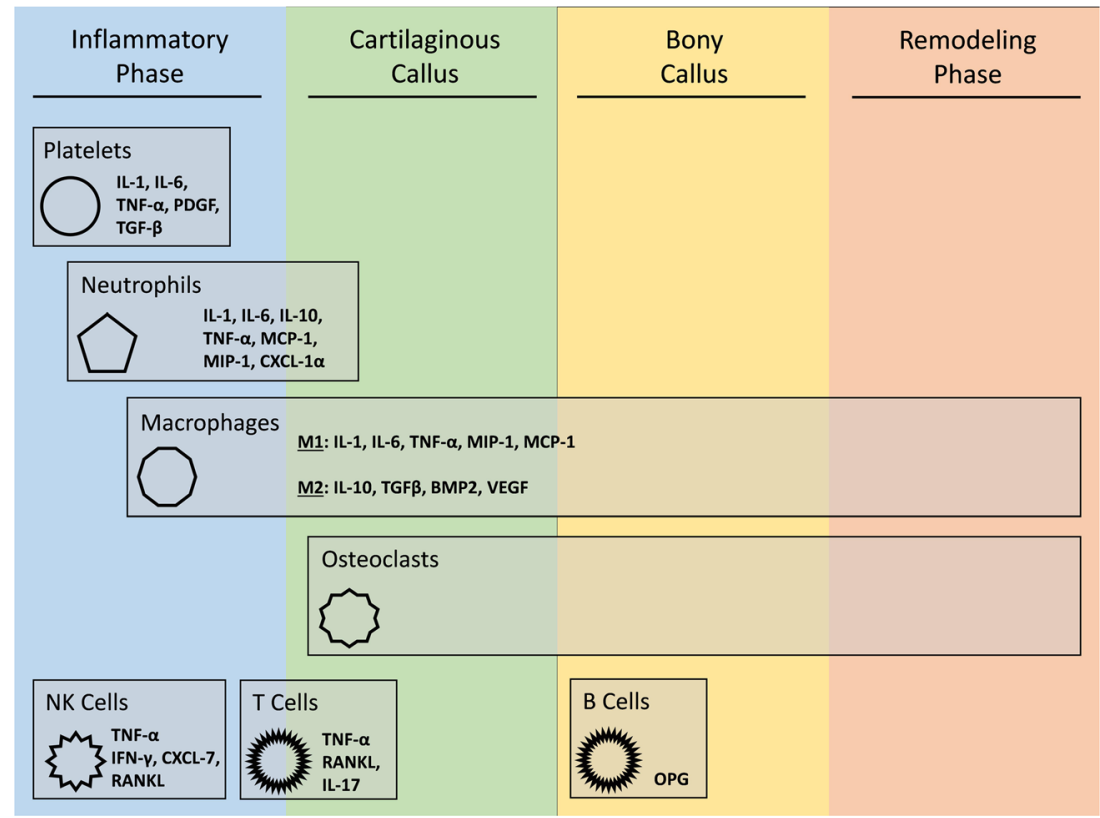

\section{Bone Fracture Healing}

Fracture repair is a complex and well-orchestrated regenerative process involving numerous signaling pathways and cell types. It follows one of two processes: (1) primary (direct) fracture repair, and (2) secondary fracture repair.

Primary fracture repair involves deposition of bone tissue: mesenchymal progenitor cells and osteoblasts are recruited and activated at the site of injury; subsequently, they deposit a bone matrix to unify the tissue [9]. This type of fracture healing occurs when the fractured bone-ends are rigidly fixed and lack relative displacement, leading to little or no inflammatory response. While this process is not likely to occur spontaneously in nature, it does ensue in fracture following fixation (such as in distraction osteogenesis in limb lengthening) [10].

Secondary fracture repair is the more common form of fracture healing observed in clinic. Bone repair occurs through a cartilaginous intermediate and in phases described below. Immune cells play a significant role in secondary bone repair.

\section{Inflammatory Phase}

Long-bone fracture healing is likened to endochondral ossification seen during embryonic development, but a key difference is the presence of an inflammatory phase during the former. When a fracture occurs, there is a local disruption of the vascularization and soft tissue. In response to this vascular injury, a hematoma forms and will act as the future template for callus formation [11]. Immune cells, including platelets, neutrophils, and macrophages are then recruited to the site and activated $[12,13]$. These cells invade the hematoma and secrete growth factors and cytokines, which help to recruit mesenchymal cells. The hematoma is reorganized and there is deposition of a fibrin thrombus $[11,12]$. As capillaries invade the thrombus, granulation tissue replaces the fibrin clot. Neutrophils and macrophages remove dead cells and debris [14]. They also release factors that promote the recruitment of mesenchymal progenitor cells that originate from the periosteum, bone marrow, and systemic circulation $[15,16]$. These cells, in turn, have an immunosuppressive character which helps to resolve the inflammation at the site and prepare it for the next stage of healing [17-21].

\section{Cartilaginous Callus Formation}

During the inflammatory phase, mesenchymal progenitor cells are recruited to the site of injury and undergo chondrogenic differentiation. It is the decreased mechanical stability at the fracture site that promotes this chondrogenesis. The granulation tissue is replaced by a fibrocatilaginous callus which poses a semi-rigid quality to provide mechanical support $[8,11]$. Initially, this cartilaginous callus is largely avascular; however, as healing proceeds, the callus is invaded by endothelial cells, promoting angiogenesis [22]. This induces terminal differentiation of chondrocytes, resulting in hypertrophy and the production of mineralized cartilaginous matrix $[8$, 23]. The fate of these chondrocytes is now debated as either undergoing apoptosis or undergoing trans-differentiation/dedifferentiation to osteogenic cells [24].

\section{Bony Callus Formation}

Upon calcification of the fracture callus, osteoprogenitor cells are recruited from the periosteum, bone marrow, vasculature, and surrounding tissue to initiate osteogenesis and the deposition of 
bone onto the calcified cartilage [8]. Simultaneously, osteoclasts are activated at the site and begin to resorb the cartilaginous callus. This results in the replacement of the cartilaginous callus with the bony callus, which is composed of woven bone and provides greater stability than the fibrocartilaginous callus [25]. Macrophages and T and B cells have been shown to play a role during mineralization (discussed below); however, their function has yet to be elucidated.

\section{Remodeling Phase}

The remodeling phase marks the last stage of fracture repair. Woven bone within the callus is replaced with laminar bone, consisting of a highly organized matrix of collagen fibers; therefore restoring the original structure and function of the bone [11]. This process is driven by osteoclast-mediated bone resorption followed by osteoblast-mediated bone formation [8].

\section{Immune Cells and Fracture Healing}

As described, fracture repair is a complex process requiring a well-organized response from multiple cell-types. During the inflammatory phase; clot formation, tissue granulation, and cell recruitment are necessary first steps which are dependent on the coordination of various immune cells. Throughout the different phases, hematopoietic cells appear to direct mesenchymal cell differentiation and activity. New information is rapidly being uncovered as osteoimmunity is a developing field. The following is a summary of immune cell types and their observed roles in fracture healing.

\section{Immune cell function and origin}

Hematopoietic cells arise from the mesoderm during embryonic development and locate to numerous sites in the human body. Along with the spleen, the bone marrow serves as a primary source for hematopoietic cells during adulthood: from within it all cells of the hematopoietic lineage can be differentiated. These cells play important roles in staving off infection and identifying foreign bodies; they are divided into two groups: cells of the lymphoid lineage and cells of the myeloid lineage. The majority of the cells located within the bone marrow cavity remain in a quiescent, multipotent state and are activated upon stimulus. Bone injury often results in bleeding; damage to the local vasculature serves as an activation step to recruit and activate these cells.

\section{Platelets}

Platelets are non-nucleated cells of the myeloid lineage. Their primary function lies in blood clotting; however, they have been shown to have a role in fracture healing [26]. Soon after injury, circulating platelets arrive at the affected site and are activated by the thrombin released in response to injured vasculature. Activated platelets take part in creating the fibrin thrombus. This acts as a scaffold for cellular engraftment as platelets secrete inflammatory cytokines (IL-1, IL-6, TNF- $\alpha$ ) and growth factors (PDGF, TGF-beta) to recruit other immune cells (neutrophils and monocytes) and mesenchymal progenitor cells respectively [27-29].

\section{Neutrophils}

Neutrophils are phagocytic cells of the myeloid lineage. As described, neutrophils are recruited by IL- 1 , TNF- $\alpha$ secreted by platelets $[30,31]$. The role of neutrophils in fracture healing is still being elucidated and involves many aspects of tissue repair. During early stages of the inflammatory phase, neutrophils have been shown to contribute to the fibrin thrombus by depositing a fibronectin matrix [32]. During the later stages of the inflammatory phase, neutrophils take part in removing cellular and tissue debris and are implicated in removal of the thrombus [33-35]. However, their most significant role seems to involve the secretion of cytokines (IL-1, IL-6, IL10 , TNF- $\alpha$, MCP-1, CXCL-1 $\alpha$, MIP-1) to attract monocytes, which will differentiate to macrophages [36-39].

\section{Macrophages}

Macrophages are phagocytic cells of the myeloid lineage. They are differentiated from monocytes. These cells play an integral part in bone homeostasis as well as bone fracture repair. During homeostasis, macrophages likely act as niche cells to osteoblasts and to osteoclasts, taking part in the crosstalk and communication to maintain the balance in bone remodeling. Indeed, our work shows that ablation of macrophages retards early skeletal growth and development resulting in decreased trabecular number and decreased bone mineral density and later leads to osteoporosis [40॰].

The importance of macrophages in fracture healing is still being investigated. The depletion of macrophages during bone fracture healing delays bone union $[5,40 \bullet, 41]$. Fracture calluses from mice in which macrophages had been ablated developed smaller, under-mineralized fracture calluses with increased amounts of fibrotic tissue. Furthermore, depletion of macrophages decreased the number of mesenchymal progenitor cells and inhibited the ability of these cells to differentiate to osteoblasts $[40 \bullet, 42 \bullet \bullet$.

In fracture healing, monocytes are recruited to the site of injury by MIP-1 (also known as CXCL2) primarily, and by IL-1 and TNF- $\alpha$. They subsequently differentiate to macrophages that have a sliding scale of functional attributes dependent on their "polarization", which is induced by extracellular signals and is thought to be reversible in vivo [43]. At one end, macrophages undergo programming to become classically 
activated M1 macrophages when exposed to inflammatory cytokines (IL-1, TNF- $\alpha$ ). These are inflammatory macrophages that further secrete IL-1, IL-6, TNF- $\alpha$, MCP-1, and MIP-1 to maintain recruitment of monocytes. They perform phagocytosis to remove necrotic cells as well as the fibrin thrombus [45]. At the other end of the sliding scale are the alternatively activated M2 macrophages, which are functional after exposure to IL4. These cells initiate an anti-inflammatory response in the later stages of inflammation as they secrete tissue repair signals (IL10, TGF-beta, BMP-2, and VEGF), recruit mesenchymal progenitor cells, induce osteochondral differentiation, and prompt angiogenesis [46-50].

The importance of macrophages in tissue homeostasis has be confirmed in other tissues as well [44-47]. Interestingly, tissue-resident macrophages have been found to be of benefit to tissue health while macrophages derived from circulating monocyte have been found to be less efficient [48]. Recently, the existence of tissue resident macrophages in bone (termed Osteomacs) has been proposed [42••, 49]. The comparative importance of tissue-resident versus monocyte-driven macrophages in bone biology has yet to be elucidated.

\section{Osteoclasts}

Osteoclasts are multinucleated cells of the myeloid lineage; they differentiate directly from monocytes, although they can also arise from macrophages [50].

Although osteoclasts are not traditionally thought of as immune cells, they are able to act as innate immune cells within bone as inflammatory signals lead to differentiation and activation of osteoclasts [51].

Osteoclasts are specialized cells as they are the only cells that resorb bone matrix [52]. Their primary role is that of a 'bone phagocyte'. They are responsible for debridement, resorption of the cartilaginous callus, resorption of the bony callus, resorbing the tunnels required for vasculature and nerves, and together with osteoblasts balance bone remodeling [25]. Upon activation, osteoclasts adhere to the bone surface, form a ruffled border, and create a tight seal with the mineralized surface termed a resorption pit [52]. This sealed compartment is then acidified by pumping in hydrogen ions to dissolve the hydroxyapatite crystal and lysosomal enzymes are secreted into the resorption pit to digest the proteinaceous material.

Recently, studies have further elucidated the immune cell signaling that regulates osteoclast activation. During fracture healing, monocytes are recruited to the site and differentiate to osteoclasts. Osteoclasts, which reside on mineralized bone surfaces, are primarily activated by receptor activator of nuclear factor kappa-B ligand (RANKL) binding to the osteoclast cell surface receptor RANK. Osteoblasts appear to be the primary source of RANKL during homeostasis and fracture healing; however, NK cells and activated T cells are also able to produce RANKL during fracture healing. Conversely, osteoprotegerin (OPG) is a decoy receptor that binds to RANK and inhibits RANKL binding, thereby preventing osteoclast activation. OPG is secreted by osteoblasts during homeostasis and fracture healing and by B cells during fracture healing.

This inflammatory signaling combines with a resorptionbased signaling to create the communication mechanism that regulates bone remodeling. As osteoclasts resorb the bone matrix, proteins such as bone sialoprotein and osteopontin, which are intercalated within the mineralized matrix and bound to collagen and hydroxyapatite, are freed and able to signal to local osteoblasts as the RGD motif of these proteins binds to the $\alpha_{\mathrm{v}} \beta_{3}$ cell surface receptor $[53,54]$.

\section{T-Lymphocytes and B-Lymphocytes}

T lymphocytes and B lymphocytes (also known as T cells and B cells) are hematopoietic cells of the lymphoid lineage. They constitute the two cell types of adaptive immunity and while their lineage can be further classified and subdivided, for the purpose of this review they will simply be classified as T cells and B cells. Depletion of T cells or of B cells leads to diminished bone health and decreased fracture healing $[55,56]$. Mice lacking $\mathrm{T}$ cells and $\mathrm{B}$ cells have been shown to have stiffer bones that are more susceptible to fracture [57].

T cells and B cells seem to have cell-signaling roles near the end of the inflammatory phase and again during the mineralization phase [58]. During later stages of the inflammatory phase, T cells produce RANKL to recruit, differentiate, and activate osteoclasts; likely in an effort to remove the fibrin thrombus in preparation of the cartilaginous callus. During this time, B cells are involved in suppression of the proinflammatory signals IFN- $\gamma, \mathrm{TNF}-\alpha$, and IL-2 [59]. Concurrently, B cells produce OPG, thereby regulating osteoclastic differentiation and activity [60-62].

Recent findings have placed more attention on the role of the cytokine IL-17 secreted by T cells. IL-17 has been shown to be an immunomodulator, able to induce anti-inflammatory functions from mesenchymal stromal cells [63] and has been shown to induce osteogenic differentiation and activity, aiding in osteoblast maturation [56]. Furthermore, IL-17 plays a role during the remodeling phase of the fracture callus as it increases expression and secretion of RANKL, leading to enhanced proliferation and activation of osteoclasts [64].

\section{Natural Killer Cells}

Natural killer cells (NK cells) are hematopoietic cells of the lymphoid lineage. The immunological function of NK cells is to recognize foreign or virally infected cells and induce apoptosis or cell lysis through cytotoxic granules [65]. Little is known about the function of natural killer cells in fracture healing. It is possible that NK cells play a role in removal of damaged cells located at the site of injury; however, conditions 
at the fracture site have been shown to inhibit NK cell-based cell lysis [66]. It is more likely that NK cells play a signaling role in debridement of the injured tissue recruiting inflammatory cells and osteoclasts as they are known to produce IFN- $\gamma$ and RANKL [67]. NK cells may also play a role in tissue deposition through recruitment of mesenchymal progenitor cells at a later stage of fracture repair as they secrete CXCL7 [68].

\section{Mesenchymal Signals to Immune Cells}

The term "licensing" has been coined to describe the antiinflammatory response of mesenchymal stromal cells (MSCs) to inflammatory cytokines secreted by immune cells [69]. IL-17 secreted by T-lymphocytes induces an iNOSbased immunosuppressive response in MSCs [63]. Secretion of TNF- $\alpha$ by immune cells has been shown to induce antiinflammatory activity of MSC population via activation of NF- $k B$ [70]. Using models of graft versus host disease, INF- $\gamma$ was identified in licensing MSCs to help suppress the immune response [71]. Interestingly, IL- $1 \alpha$ or IL- $1 \beta$ alone are not able to elicit a licensing response from MSCs but do so in the presence of INF- $\gamma$ [72]. Novel interactions and the effects of inflammatory molecules on mesenchymal cells continue to be discovered. As this phenomenon is studied, the information gained may help to shed light on processes involved in bone fracture healing and potential therapeutic interventions.

\section{Immune Dysfunction and Fracture Healing}

In the clinical setting, the importance of healthy immune function on fracture healing is clear. Neither a muted nor an elevated immune response is advantageous during bone fracture healing. HIV-positive patients display slower bone fracture healing, increased occurrence of fragility fractures, and increased risk of developing osteoporosis [73]. Conversely, in conditions of autoimmune disease, such as lupus or rheumatoid arthritis, bone fracture healing is also inhibited [74, 75]. With chronic inflammation, as in diabetes, obesity, or aging, inflammatory signaling and processing are dysregulated, leading to a chronic state of elevated inflammation, which is associated with poor fracture healing [37]. For example, in diabetes, increased levels of TNF- $\alpha$ lead to increased apoptosis of chondrocytes and premature resorption of the cartilaginous callus [76, 77].

\section{Inflammatory Cells as a Target for Treatment?}

In aged patients, fracture healing occurs at a slower pace and has a higher occurrence of non-union than in young patients. In conditions of metabolic dysregulation, fracture repair is likewise hindered and often results in bone that is weaker than the original tissue [78]. This lack of structural integrity leads to a higher rate of re-fracture and a higher rate of revision surgery in implants. The information gained from investigating osteoimmunology in fracture healing could lead to novel treatment strategies and a better prognosis for bone injury patients.

Scaffolds made of various biomaterials have been employed in the surgical management of non-healing fractures. These scaffolds provide the structural template for tissue regeneration. Historically, these scaffolds were designed to be inert to minimize the host's immune response to the foreign body. However, these scaffolds often lead to activation of the innate and adaptive immune system [79]. Since then, our understanding of the immune response in wound healing has vastly improved, and there has been a growing interest in developing scaffolds with immune-modulating capacities. Recent studies have shown that various biomaterials can affect in vivo macrophage function, altering the polarization of macrophages [80-82]. Most of these studies have been performed on animal models. It remains to be seen whether these scaffolds will elicit similar effects in humans.

Efforts to modulate the immune system to improve fracture repair has been documented in the literature. Platelet-rich plasma (PRP) therapy is an autologous blood product in which patient's own platelets have been concentrated, and injected locally at the site of injury [83-86]. Although there are some studies suggesting improvement in fracture healing with PRP therapy in humans, the sample size of these studies were small and only a few were randomized controlled studies. While platelets may play a role in the initial inflammatory cascade, the mechanism by which concentrated platelets promote fracture healing is largely unknown.

\section{Conclusion}

Immune cells play a critical role in bone fracture healing. These cells serve as the initial responders at the site of injury, mending vasculature, and initiating cascades of signals to recruit cells to carry out the repair processes. Osteoimmunity is a developing research field and more work must be done to better appreciate the biological significance of immune cells in bone regeneration.

\section{Compliance with Ethical Standards}

Conflict of Interest Benjamin Alman and Gurpreet Baht declare no conflict of interest.

Human and Animal Rights and Informed Consent This article does not contain any studies with human or animal subjects performed by any of the authors. 
Open Access This article is distributed under the terms of the Creative Commons Attribution 4.0 International License (http:// creativecommons.org/licenses/by/4.0/), which permits unrestricted use, distribution, and reproduction in any medium, provided you give appropriate credit to the original author(s) and the source, provide a link to the Creative Commons license, and indicate if changes were made.

\section{References}

Papers of particular interest, published recently, have been highlighted as:

- Of importance

•- Of major importance

1. Tzioupis C, Giannoudis PV. Prevalence of long-bone non-unions. Injury. 2007;38(Suppl 2):S3-9.

2. Clement ND, Beauchamp NJ, Duckworth AD, McQueen MM, Court-Brown CM. The outcome of tibial diaphyseal fractures in the elderly. Bone Joint J. 2013;95-B(9):1255-62.

3. Miranda MAMSM. Treatment strategy for non unions and malunions. New York: Thieme; 2007.

4. Ng AH, Baht GS, Alman BA, Grynpas MD. Bone marrow stress decreases osteogenic progenitors. Calcif Tissue Int. 2015;97(5): 476-86.

5. Xing Z, Lu C, Hu D, Miclau T III, Marcucio RS. Rejuvenation of the inflammatory system stimulates fracture repair in aged mice. $\mathrm{J}$ Orthop Res. 2010;28(8):1000-6.

6. Schmidt-Bleek K, Schell H, Schulz N, Hoff P, Perka C, Buttgereit $\mathrm{F}$, et al. Inflammatory phase of bone healing initiates the regenerative healing cascade. Cell Tissue Res. 2012;347(3):567-73.

7. Lienau J, Schmidt-Bleek K, Peters A, Haschke F, Duda GN, Perka $\mathrm{C}$, et al. Differential regulation of blood vessel formation between standard and delayed bone healing. J Orthop Res. 2009;27(9): 1133-40.

8. Schindeler A, McDonald MM, Bokko P, Little DG. Bone remodeling during fracture repair: The cellular picture. Semin Cell Dev Biol. 2008;19(5):459-66.

9. Loi F, Cordova LA, Pajarinen J, Lin TH, Yao Z, Goodman SB. Inflammation, fracture, and bone repair. Bone. 2016;86:119-30.

10. Ai-Aql ZS, Alagl AS, Graves DT, Gerstenfeld LC, Einhorn TA. Molecular mechanisms controlling bone formation during fracture healing and distraction osteogenesis. J Dent Res. 2008;87(2):107-18.

11. Marsell R, Einhorn TA. The biology of fracture healing. Injury. 2011;42(6):551-5.

12. Ozaki A, Tsunoda M, Kinoshita S, Saura R. Role of fracture hematoma and periosteum during fracture healing in rats: Interaction of fracture hematoma and the periosteum in the initial step of the healing process. J Orthop Sci. 2000;5(1):64-70.

13. Kolar P, Schmidt-Bleek K, Schell H, Gaber T, Toben D, Schmidmaier $\mathrm{G}$, et al. The early fracture hematoma and its potential role in fracture healing. Tissue Eng Part B Rev. 2010;16(4):427-34.

14. Thomas MV, Puleo DA. Infection, inflammation, and bone regeneration: A paradoxical relationship. J Dent Res. 2011;90(9):1052-61.

15. Einhorn TA. The cell and molecular biology of fracture healing. Clin Orthop Relat Res. 1998;(355 Suppl):S7-21.

16. Colnot C, Huang S, Helms J. Analyzing the cellular contribution of bone marrow to fracture healing using bone marrow transplantation in mice. Biochem Biophys Res Commun. 2006;350(3):557-61

17. Jiang XX, Zhang Y, Liu B, Zhang SX, Wu Y, Yu XD, et al. Human mesenchymal stem cells inhibit differentiation and function of monocyte-derived dendritic cells. Blood. 2005;105(10):4120-6.
18. Nemeth K, Keane-Myers A, Brown JM, Metcalfe DD, Gorham JD, Bundoc VG, et al. Bone marrow stromal cells use TGF-beta to suppress allergic responses in a mouse model of ragweed-induced asthma. Proc Natl Acad Sci USA. 2010;107(12):5652-7.

19. Nemeth K, Leelahavanichkul A, Yuen PS, Mayer B, Parmelee A, Doi $\mathrm{K}$, et al. Bone marrow stromal cells attenuate sepsis via prostaglandin $\mathrm{E}(2)$-dependent reprogramming of host macrophages to increase their interleukin-10 production. Nat Med. 2009;15(1):42-49.

20. DelaRosa O, Lombardo E, Beraza A, Mancheno-Corvo P, Ramirez $\mathrm{C}$, Menta R, et al. Requirement of IFN-gamma-mediated indoleamine 2,3-dioxygenase expression in the modulation of lymphocyte proliferation by human adipose-derived stem cells. Tissue Eng. Part A. 2009;15(10):2795-806.

21. Rafei M, Campeau PM, Aguilar-Mahecha A, Buchanan M, Williams P, Birman E, et al. Mesenchymal stromal cells ameliorate experimental autoimmune encephalomyelitis by inhibiting CD4 Th17 T cells in a CC chemokine ligand 2-dependent manner. J Immunol. 2009;182(10):5994-6002.

22. Carano RA, Filvaroff EH. Angiogenesis and bone repair. Drug Discov Today. 2003;8(21):980-9.

23. Dimitriou R, Tsiridis E, Giannoudis PV. Current concepts of molecular aspects of bone healing. Injury-International J Care Injured. 2005;36(12):1392-404.

24. Yang L, Tsang KY, Tang HC, Chan D, Cheah KS. Hypertrophic chondrocytes can become osteoblasts and osteocytes in endochondral bone formation. Proc Natl Acad Sci USA. 2014;111(33): 12097-102.

25. McKibbin B. The biology of fracture healing in long bones. J Bone Joint Surg Br. 1978;60-B(2):150-62.

26. Roldan JC, Jepsen S, Miller J, Freitag S, Rueger DC, Acil Y, et al. Bone formation in the presence of platelet-rich plasma vs. bone morphogenetic protein-7. Bone. 2004;34(1):80-90.

27. Jingushi S, Scully SP, Joyce ME, Sugioka Y, Bolander ME. Transforming growth factor-beta 1 and fibroblast growth factors in rat growth plate. J Orthop Res. 1995;13(5):761-8.

28. Dimitriou R, Tsiridis E, Giannoudis PV. Current concepts of molecular aspects of bone healing. Injury. 2005;36(12):1392-404.

29. Dulgeroglu TC, Metineren H. Evaluation of the effect of plateletrich fibrin on long bone healing: An experimental rat model. Orthopedics. 2017;40(3):e479-e84.

30. Furze RC, Rankin SM. Neutrophil mobilization and clearance in the bone marrow. Immunology. 2008;125(3):281-8.

31. Sadik CD, Kim ND, Luster AD. Neutrophils cascading their way to inflammation. Trends Immunol. 2011;32(10):452-60.

32. Bastian OW, Koenderman L, Alblas J, Leenen LP, Blokhuis TJ. Neutrophils contribute to fracture healing by synthesizing fibronectin+ extracellular matrix rapidly after injury. Clin Immunol. 2016;164:78-84.

33. Xian CJ, Zhou FH, McCarty RC, Foster BK. Intramembranous ossification mechanism for bone bridge formation at the growth plate cartilage injury site. J Orthop Res. 2004;22(2):417-26.

34. Segal AW. How neutrophils kill microbes. Annu Rev Immunol. 2005;23:197-223

35. Timlin M, Toomey D, Condron C, Power C, Street J, Murray P, et al. Fracture hematoma is a potent proinflammatory mediator of neutrophil function. J Trauma. 2005;58(6):1223-9.

36. Soehnlein O, Lindbom L, Weber C. Mechanisms underlying neutrophil-mediated monocyte recruitment. Blood. 2009;114(21): 4613-23.

37. Claes L, Recknagel S, Ignatius A. Fracture healing under healthy and inflammatory conditions. Nat Rev Rheumatol. 2012;8(3):133-43.

38. Kovtun A, Bergdolt S, Wiegner R, Radermacher P, Huber-Lang M, Ignatius A. The crucial role of neutrophil granulocytes in bone fracture healing. Eur Cell Mater. 2016;32:152-62.

39. Scapini P, Laudanna C, Pinardi C, Allavena P, Mantovani A, Sozzani S, et al. Neutrophils produce biologically active 
macrophage inflammatory protein-3alpha (MIP-3alpha)/CCL20 and MIP-3beta/CCL19. Eur J Immunol. 2001;31(7):1981-8.

40. Baht GS, Silkstone D, Vi L, Nadesan P, Amani Y, Whetstone H, et al. Erratum: Exposure to a youthful circulation rejuvenates bone repair through modulation of beta-catenin. Nat Commun. 2015;6: 7761. Using parabiosis, bone marrow transplantation, and conditioned media, the authors show that hematapoeitec (CD45+) play an important role in fracture healing and osteoblastic differentiation.

41. Raggatt LJ, Wullschleger ME, Alexander KA, Wu AC, Millard SM, Kaur S, et al. Fracture healing via periosteal callus formation requires macrophages for both initiation and progression of early endochondral ossification. Am J Pathol. 2014;184(12):3192-204.

42.• Chang MK, Raggatt LJ, Alexander KA, Kuliwaba JS, Fazzalari NL, Schroder K, et al. Osteal tissue macrophages are intercalated throughout human and mouse bone lining tissues and regulate osteoblast function in vitro and in vivo. J Immunol. 2008;181(2): 1232-44. This work indicates, for the first time, the presence of (bone) tissue-specific macrophages.

43. Mosser DM, Edwards JP. Exploring the full spectrum of macrophage activation. Nat Rev Immunol. 2008;8(12):958-69.

44. Godwin JW, Pinto AR, Rosenthal NA. Macrophages are required for adult salamander limb regeneration. Proc Natl Acad Sci USA. 2013;110(23):9415-20.

45. Mescher AL. Macrophages and fibroblasts during inflammation and tissue repair in models of organ regeneration. Regeneration (Oxf). 2017;4(2):39-53.

46. Juban G, Chazaud B. Metabolic regulation of macrophages during tissue repair: insights from skeletal muscle regeneration. FEBS Lett. 2017.

47. Godwin JW, Pinto AR, Rosenthal NA. Chasing the recipe for a proregenerative immune system. Semin Cell Dev Biol. 2017;61:71-9.

48. Lavine KJ, Epelman S, Uchida K, Weber KJ, Nichols CG, Schilling JD, et al. Distinct macrophage lineages contribute to disparate patterns of cardiac recovery and remodeling in the neonatal and adult heart. Proc Natl Acad Sci USA. 2014;111(45):16029-34.

49. Pettit AR, Chang MK, Hume DA, Raggatt LJ. Osteal macrophages: a new twist on coupling during bone dynamics. Bone. 2008;43(6): 976-82.

50. Udagawa N, Takahashi N, Akatsu T, Tanaka H, Sasaki T, Nishihara $\mathrm{T}$, et al. Origin of osteoclasts: mature monocytes and macrophages are capable of differentiating into osteoclasts under a suitable microenvironment prepared by bone marrow-derived stromal cells. Proc Natl Acad Sci USA. 1990;87(18):7260-4.

51. Wu Y, Humphrey MB, Nakamura MC. Osteoclasts - the innate immune cells of the bone. Autoimmunity. 2008;41(3):183-94.

52. Boyle WJ, Simonet WS, Lacey DL. Osteoclast differentiation and activation. Nature. 2003;423(6937):337-42.

53. Baht GS, O'Young J, Borovina A, Chen H, Tye CE, Karttunen M, et al. Phosphorylation of Ser136 is critical for potent bone sialoprotein-mediated nucleation of hydroxyapatite crystals. Biochem J. 2010;428(3):385-95.

54. Ganss B, Kim RH, Sodek J. Bone sialoprotein. Crit Rev Oral Biol Med. 1999;10(1):79-98.

55. Toben D, Schroeder I, El Khassawna T, Mehta M, Hoffmann JE, Frisch JT, et al. Fracture healing is accelerated in the absence of the adaptive immune system. J Bone Miner Res. 2011;26(1):113-24.

56. Nam D, Mau E, Wang Y, Wright D, Silkstone D, Whetstone H, et al. T-lymphocytes enable osteoblast maturation via IL-17F during the early phase of fracture repair. PLoS One. 2012;7(6):e40044.

57. El Khassawna T, Serra A, Bucher CH, Petersen A, Schlundt C, Konnecke I, et al. T lymphocytes influence the mineralization process of bone. Front Immunol. 2017;8:562.

58. Konnecke I, Serra A, El Khassawna T, Schlundt C, Schell H, Hauser $\mathrm{A}$, et al. T and $\mathrm{B}$ cells participate in bone repair by infiltrating the fracture callus in a two-wave fashion. Bone. 2014;64:155-65.
59. Sun GJ, Wang YC, Ti YF, Wang J, Zhao JN, Qian HB. Regulatory $\mathrm{B}$ cell is critical in bone union process through suppressing proinflammatory cytokines and stimulating Foxp3 in Treg cells. Clin Exp Pharmacol P. 2017;44(4):455-62.

60. Kong YY, Feige U, Sarosi I, Bolon B, Tafuri A, Morony S, et al. Activated $\mathrm{T}$ cells regulate bone loss and joint destruction in adjuvant arthritis through osteoprotegerin ligand. Nature. 1999;402(6759):304-9.

61. Manabe N, Kawaguchi H, Chikuda H, Miyaura C, Inada M, Nagai $\mathrm{R}$, et al. Connection between B lymphocyte and osteoclast differentiation pathways. J Immunol. 2001;167(5):2625-31.

62. Takayanagi H. Osteoimmunology: shared mechanisms and crosstalk between the immune and bone systems. Nat Rev Immunol. 2007;7(4):292-304.

63. Han X, Yang Q, Lin L, Xu C, Zheng C, Chen X, et al. Interleukin17 enhances immunosuppression by mesenchymal stem cells. Cell Death Differ. 2014;21(11):1758-68.

64. Huang H, Kim HJ, Chang EJ, Lee ZH, Hwang SJ, Kim HM, et al. IL-17 stimulates the proliferation and differentiation of human mesenchymal stem cells: implications for bone remodeling. Cell Death Differ. 2009;16(10):1332-43.

65. Chaplin DD. Overview of the immune response. J Allergy Clin Immunol. 2010;125(2 Suppl 2):S3-23.

66. Hauser CJ, Joshi P, Jones Q, Zhou X, Livingston DH, Lavery RF. Suppression of natural killer cell activity in patients with fracture/ soft tissue injury. Arch Surg. 1997;132(12):1326-30.

67. Soderstrom K, Stein E, Colmenero P, Purath U, Muller-Ladner U, de Matos CT, et al. Natural killer cells trigger osteoclastogenesis and bone destruction in arthritis. Proc Natl Acad Sci USA. 2010;107(29):13028-33.

68. Almeida CR, Caires HR, Vasconcelos DP, Barbosa MA. NAP-2 secreted by human NK cells can stimulate mesenchymal stem/stromal cell recruitment. Stem Cell Reports. 2016;6(4):466-73.

69. Krampera M. Mesenchymal stromal cell 'licensing': a multistep process. Leukemia. 2011;25(9):1408-14.

70. Dorronsoro A, Ferrin I, Salcedo JM, Jakobsson E, FernandezRueda J, Lang V, et al. Human mesenchymal stromal cells modulate T-cell responses through TNF-alpha-mediated activation of NF-kappaB. Eur J Immunol. 2014;44(2):480-8.

71. Polchert D, Sobinsky J, Douglas G, Kidd M, Moadsiri A, Reina E, et al. IFN-gamma activation of mesenchymal stem cells for treatment and prevention of graft versus host disease. Eur J Immunol. 2008;38(6):1745-55.

72. Ren G, Zhang L, Zhao X, Xu G, Zhang Y, Roberts AI, et al. Mesenchymal stem cell-mediated immunosuppression occurs via concerted action of chemokines and nitric oxide. Cell Stem Cell. 2008;2(2):141-50.

73. Richardson J, Hill AM, Johnston CJ, McGregor A, Norrish AR, Eastwood D, et al. Fracture healing in HIV-positive populations. J Bone Joint Surg Br. 2008;90(8):988-94.

74. Al-Sebaei MO, Daukss DM, Belkina AC, Kakar S, Wigner NA, Cusher D, et al. Role of Fas and Treg cells in fracture healing as characterized in the fas-deficient (lpr) mouse model of lupus. $\mathrm{J}$ Bone Miner Res. 2014;29(6):1478-91.

75. Briot K, Geusens P, Em Bultink I, Lems WF, Roux C. Inflammatory diseases and bone fragility. Osteoporos Int. 2017.

76. Kayal RA, Siqueira M, Alblowi J, McLean J, Krothapalli N, Faibish D, et al. TNF-alpha mediates diabetes-enhanced chondrocyte apoptosis during fracture healing and stimulates chondrocyte apoptosis through FOXO1. J Bone Miner Res. 2010;25(7):1604-15.

77. Kayal RA, Tsatsas D, Bauer MA, Allen B, Al-Sebaei MO, Kakar S, et al. Diminished bone formation during diabetic fracture healing is related to the premature resorption of cartilage associated with increased osteoclast activity. J Bone Miner Res. 2007;22(4):560-8. 
78. Tevlin R, Seo EY, Marecic O, McArdle A, Tong X, Zimdahl B, et al. Pharmacological rescue of diabetic skeletal stem cell niches. Sci Transl Med. 2017;9(372).

79. Franz S, Rammelt S, Scharnweber D, Simon JC. Immune responses to implants - a review of the implications for the design of immunomodulatory biomaterials. Biomaterials. 2011;32(28):6692-709.

80. Fuchs AK, Syrovets T, Haas KA, Loos C, Musyanovych A, Mailander V, et al. Carboxyl- and amino-functionalized polystyrene nanoparticles differentially affect the polarization profile of $\mathrm{M} 1$ and M2 macrophage subsets. Biomaterials. 2016;85:78-87.

81. Spiller KL, Nassiri S, Witherel CE, Anfang RR, Ng J, Nakazawa KR, et al. Sequential delivery of immunomodulatory cytokines to facilitate the M1-to-M2 transition of macrophages and enhance vascularization of bone scaffolds. Biomaterials. 2015;37:194-207.
82. Taraballi F, Corradetti B, Minardi S, Powel S, Cabrera F, Van Eps JL, et al. Biomimetic collagenous scaffold to tune inflammation by targeting macrophages. J Tissue Eng. 2016. https://doi.org/10.1177/ 2041731415624667.

83. Griffin XL, Wallace D, Parsons N, Costa ML. Platelet rich therapies for long bone healing in adults. Cochrane Database Syst Rev. 2012;7:CD009496.

84. Wei LC, Lei GH, Sheng PY, Gao SG, Xu M, Jiang W, et al. Efficacy of platelet-rich plasma combined with allograft bone in the management of displaced intra-articular calcaneal fractures: A prospective cohort study. J Orthop Res. 2012;30(10):1570-6.

85. Golos J, Walinski T, Piekarczyk P, Kwiatkowski K. Results of the use of platelet rich plasma in the treatment of delayed union of long bones. Ortop Traumatol Rehabil. 2014;16(4):397-406.

86. Malhotra R, Kumar V, Garg B, Singh R, Jain V, Coshic P, etal. Role of autologous platelet-rich plasma in treatment oflong-bone nonunions: a prospective study. Musculoskelet Surg. 2015;99(3):243-8. 